\title{
ENANTIOSELECTIVE REDUCTION OF PROCHIRAL KETONES PROMOTED BY AMINO AMIDE RUTHENIUM COMPLEXES: A DFT STUDY
}

\author{
Y. Meftah, ${ }^{1,2}$ Y. Boumedjane, ${ }^{3}$ P. Fleurat-Lessard, ${ }^{4}$ F. Delbecq, ${ }^{5}$ C. Michel ${ }^{5,}$ *
}

${ }^{1}$ Ecole Normale Supérieure de Boussaada, Boussaada 28201, Algérie

${ }^{2}$ Laboratoire de Chimie Appliquée, université Mohamed-Kheider de Biskra, Biskra 07000, Algérie

${ }^{3}$ Département Sciences de la Matière, université Mohamed-Kheider de Biskra, Biskra 07000, Algérie

${ }^{4}$ Institut de Chimie Moléculaire de I'Université de Bourgogne (ICMUB UMR-CNRS 6302), Université de Bourgogne Franche-Comté (UBFC), 9 avenue Alain Savary, 21078 Dijon, France

${ }^{5}$ Univ Lyon, Ens de Lyon, CNRS UMR 5182, Université Claude Bernard Lyon 1, Laboratoire de Chimie, F69342, Lyon, France

\section{KEYWORDS}

Enantioselective Reduction; Amidoamide Ruthenium Catalyst; DFT; Mechanism; Conformers.

\section{ABSTRACT}

The origin of enantioselectivity in the reaction of chiral $\mathrm{Ru}$ amino amide complexes in the asymmetric transfer hydrogenation of acetophenone was investigated using DFT calculations. For the most stable active catalysts, the full free energy profiles for the reaction were calculated according to the concerted hydrogen transfer mechanism. We succeeded in reproducing the experimentally observed enantioselectivity for the studied Ru amino amide complexes. Our results indicate that the high enantioselectivity can be explained by a stabilizing $\mathrm{CH}-\pi$ interaction existing between the phenyl group of acetophenone and the aromatic substituent of the catalyst, which plays a significant role in selectivity. Finally, our results show that important insights can be obtained with such a theoretical approach not simply to explain the origin of the reaction asymmetry but also to predict the enantiomeric excess. This can help experimentalists to design new enantioselective catalysts.

\section{INTRODUCTION}

The asymmetric hydrogenation of ketones by hydrogen transfer (ATH) is one of the largest applications of catalysis in synthetic and pharmaceutical industry.[1-3] Much effort has been devoted to design asymmetric transition-metal catalysts,[4-8] able to yield high stereoselectivities. For example, Noyori's ruthenium complexes containing arene and $\mathrm{N}$-(p-toluenesulfonyl)-1,2-diphenylethylenediamine (TsDPEN) ligands are efficient catalysts for the asymmetric hydrogenation of ketones by $\mathrm{H}$ transfer.[9] Established catalytic 
systems for asymmetric hydrogenation are typically based on expensive chiral ligands such as diamines or amino alcohols. The replacement of these ligands with cheaper amino acids and their derivatives is an ongoing quest in academia and industry. T. Ohta et al.[10] have reported the hydrogenation of ketones by $\mathrm{H}$ transfer catalyzed by $\mathrm{Ru}(\mathrm{II})$ coordinated with various amino acids. The best enantiomeric excess was obtained using proline and the selectivity was explained by the high geometric constraint imposed onto the $\mathrm{Ru}-\mathrm{N}-\mathrm{C}-\mathrm{C}(\mathrm{O})-\mathrm{N}$ chelation ring. The group of Faller studied the hydrogenation of a variety of ketones at -24 $\mathrm{C}^{\circ}$ catalyzed by $\left[(\mathrm{p} \text {-cymene }) \mathrm{RuCl}_{2}\right]_{2} / \mathrm{L}$-prolineamide that gave excellent enantiocontrol up to $93 \%$ with in situ formed Ru-precatalysts.[11] These studies have also shown that the enantioselectivity can be affected by electronic as well as steric effects of the substituents on the ketone substrate. At the same time, Chung described the first water-soluble ruthenium (II) catalyst coordinated by amides derived from (L)-proline that was active in reduction of aromatic ketones in an aqueous solution, with enantiomeric excesses up to 95.3 \%.[12,13] Moreover, several groups reported the ATH reaction catalyzed by amino amide ligands, for which excellent enantioselectivities (95.5\%) were reached with in situ formed Ru-precatalysts.[14-20] In 2015, Çetinkaya et al.[21] compared the proline amine ligands with amide analogues and also investigated the steric effect of aryl ring in the enantioselectivity. They found that the bulkiness of the aryl substituents on the ligand improved the enantioselectivity. A. Bacchi et al.[22] reported that the phenylalanine amide (ligand 1), and the proline amide (ligand 2) generate pre-catalysts with $\mathrm{Ru}\left(\mathrm{p}\right.$-cymene) $\mathrm{Cl}_{2}$ for the transfer hydrogenation of acetophenone in basic isopropanol (see Figure 1).

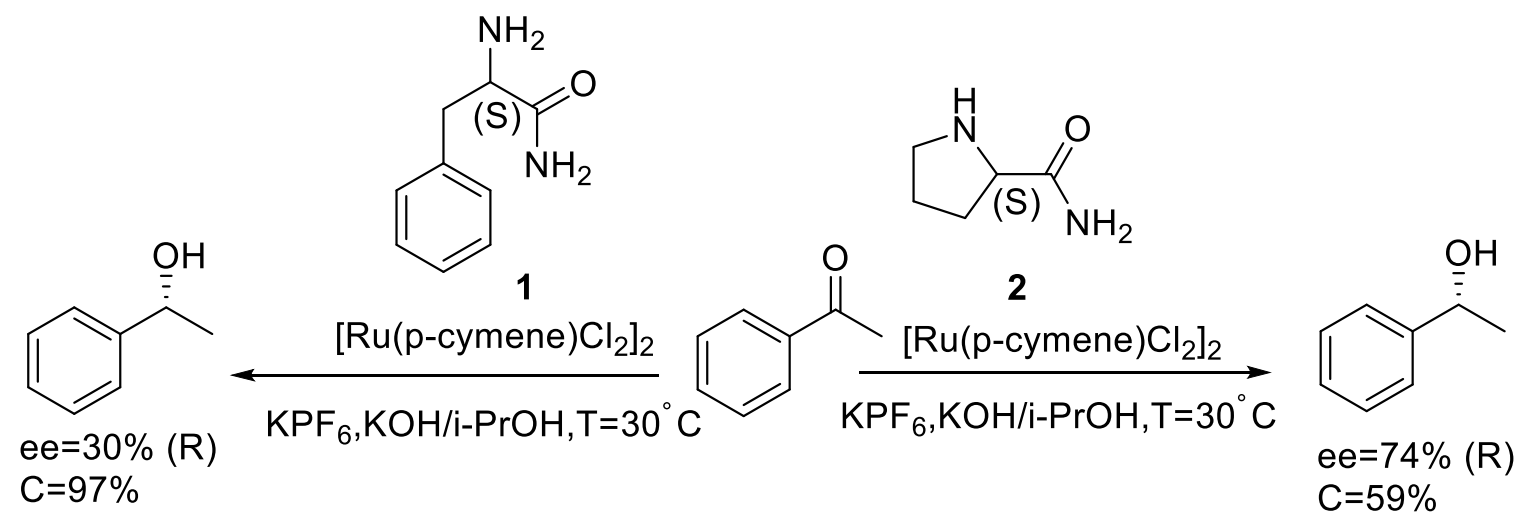

Figure 1. Ru-catalyzed ATH of ketones with $\left[\mathrm{Ru}(p-c y m e n e) \mathrm{Cl}_{2}\right]_{2}$ and (ligand 1) phenyl alanine or proline amide (ligand 2). ee and $C$ are the obtained enantiomeric excess and conversion, respectively.

They evidenced a strong impact of the choice of the ligand on the conversion and the enantiomeric excess, the less active catalyst being the more selective one (ligand 2). In this article, we aim at rationalizing the impact of the ligand on the activity and the enantiomeric excess by a study of the reaction mechanism based on the Density Functional Theory (DFT). 
In previous works, we have shown that DFT calculations are very useful for explaining the origin of the reaction asymmetry.[23,24] More specifically, several DFT studies have been reported in the literature related to the reactions catalyzed by homogeneous catalysts which has demonstrated the potential impact of this approach.[25-30] R. Abbel et al.[31] studied theoretically the hydrogenation of acetophenone by several $\mathrm{Ru}(\mathrm{H})_{2}\left(\mathrm{PPh}_{3}\right)_{2}$ (diamine) complexes. They found that the relative position of the hydrides and of the phosphines is important, the trans hydrides-cis phosphines giving the highest selectivity. The very active and selective Noyori-type catalysts for the asymmetric hydrogenation of ketones contain a chelating, enantiopure diphosphine ligand and thus, necessarily have phosphorus donors that are mutually cis. In 2012, M. Nordin et al.[32] employed DFT calculations to rationalize the enantioselectivity observed experimentally in ATH of aryl alkyl ketones with $\left[\mathrm{RhCp}^{*} \mathrm{Cl}_{2}\right]$ and hydroxamic acid-functionalized L-valine or hydroxamic acidfunctionalized derived from the amino acid L-phenylalanine.

The plausible mechanism for the transfer hydrogenation of ketones promoted by amino amide based Ru catalysts was studied experimentally by the group of P. Pelagatti.[22,33] The high-resolution MS (ESI) experiments of precatalytic solutions indicate that the catalytic process is governed by a bifunctional mechanism, analogous to that proposed by Noyori et al.[34,35] and shown in Figure 2. The deprotonation of the pre-catalyst by two equivalents of a strong base such as $\mathrm{KOH}$ leads to a 16-electron intermediate in which the amino-amido ligand is deprotonated both on the amino and the amido function. Then, a ruthenium hydride $(\mathrm{Ru}-\mathrm{H})$ is formed together with the reprotonation of the amine $(\mathrm{N}-\mathrm{H})$ via TSa by the reaction of this 16-electrons intermediate with the hydrogen donor (isopropanol). The key step is the simultaneous transfer of the hydridic $\mathrm{H}(\mathrm{Ru}-\mathrm{H})$ and the protic $\mathrm{H}(\mathrm{N}-\mathrm{H})$ to the $\mathrm{C}=\mathrm{O}$ functional group of acetophenone via a six-membered transition state TSb. Last, the active 16-electrons intermediate is regenerated with the release of the chiral alcohol, closing the catalytic cycle. 


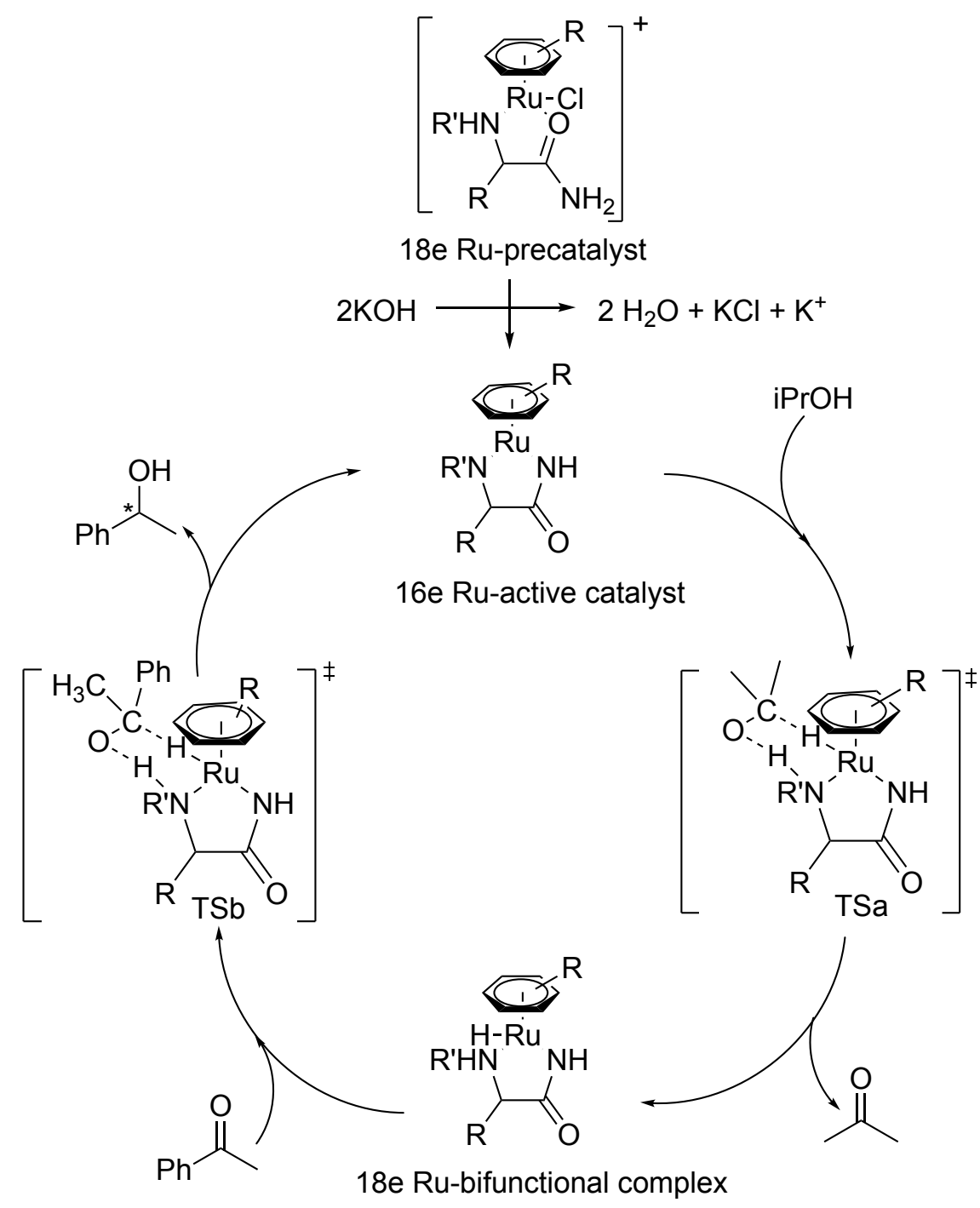

Figure 2. Plausible mechanism for ATH of acetophenone catalyzed by Ru(II) complexes containing amino amide ligands.

We based our approach on this plausible mechanism and compared the reaction profiles of the full cycle for both catalysts (ligand 1 and ligand 2 in Figure 1 ) by the means of DFT calculations. In particular, we aim at explaining the low selectivity in favor of the $R$ isomer (ee=30\%) obtained with ligand 1 (Phenylalanine amide) and the high conversion $\mathrm{C}=97 \%$ while the selectivity is higher (ee=74\%) with ligand 2 (proline amide) affording also the $R$ isomer but the conversion is low $C=59 \%$ (Figure 1 ).

\section{COMPUTATIONAL METHODS}

In this study, no simplification was made in any of the reactant molecules selected for the computational study. ATH of acetophenone was chosen for the theoretical calculations, employing $\left[\left\{\mathrm{RuCl}_{2}(\text { para-cymene })\right\}_{2}\right]$, proline amide or phenyl alanine amide as the ligand, and isopropyl alcohol (IPA) as solvent and hydrogen source. 
All the calculations presented herein were carried out by means of density functional theory (DFT). After an extensive study of several functionals (see SI),[36] the M06[37,38] functional was chosen. Interestingly, Truhlar showed that the M06 functional is adapted to describe $\mathrm{CH}-\pi$ interactions.[39] For the geometry optimization, the 6-31G(d,p) basis set was used for the $\mathrm{Cl}, \mathrm{C}, \mathrm{N}, \mathrm{O}$, and $\mathrm{H}$ elements and the LANL2TZ pseudopotential and basis set for ruthenium.[39] This basis set will be denoted by BS1 in the following. The solvation energies were calculated as single-point corrections on the optimized structures using LANL2TZ(f) for $\mathrm{Ru}$ and the larger $6-311+\mathrm{G}(2 \mathrm{~d}, 2 \mathrm{p})$ for the others elements with the propan-2-ol described in the SMD solvation model.[40] Transition states free energies were finally corrected for BSSE using the Boys\&Bernardi approach.[41] We confirmed that all reactants and intermediates have no imaginary frequencies, and that each transition structure has one, and only one, imaginary frequency. Intrinsic reaction coordinate (IRC) calculations, at the M06/BS1 level of theory, were performed to ensure that the transition structures led to the expected reactants and products. All free energies were calculated at $298.15 \mathrm{~K}$ and included the solvation free energies. All the calculations were performed by using the Gaussian09 D01 program package.[42]

\section{RESULTS AND DISCUSSIONS}

The mechanistic discussion is divided into three sections following the three major steps of the reaction mechanism represented in Figure 2. To start with, we focus on the formation of the active catalyst. Then, we discuss the results concerning the formation of the bifunctional ruthenium complex. Finally, we present the results for the ATH and provide an explanation for the enantioselectivity observed in the catalytic system.

\section{1-Formation of the 16e Ruthenium active catalyst}

By treatment of the precatalyst $\left[\left(\eta^{6}-p \text {-cymene }\right) \mathrm{Ru}\left(\mathrm{K}^{2}-\mathrm{O}, \mathrm{N} \text {-amino-amido }\right) \mathrm{Cl}\right]^{+}$with excess of $\mathrm{KOH}$, the deprotonation of the amide function leads to the formation of the active catalyst (16e) $\left[\left(\eta^{6}-p\right.\right.$-cymene)Ru( $\kappa^{2}-$ $\mathrm{N}, \mathrm{N}^{\prime}$-bis-aminoamidato $\left.)\right]$. The resulting catalysts $\left[\left(\eta^{6}-p\right.\right.$-cymene $)-\mathrm{Ru}\left(\mathrm{K}^{2}-\mathrm{N}, \mathrm{N}^{\prime}-\mathrm{bis}-(\mathrm{L})\right.$ phenylalanine-amidato $\left.)\right]$ and $\left[\left(\eta^{6}-p\right.\right.$-cymene)-Ru( $\mathrm{K}^{2}-\mathrm{N}, \mathrm{N}^{\prime}$-bis-(L)proline-amidato $\left.)\right]$ will be denominated Cat-1 and Cat-2 respectively in the following.

In Cat-1, both the phenyl of the phenyl alanine and the $p$-cymene can rotate to generate different conformations during the reaction.[43]'[44] Cat-2 is more constrained because only the $p$-cymene can freely rotate.[45] We systematically screened for the best conformer along the reaction pathway as detailed in supplementary information (Figure S11, Table S1 and Table S2 and the related discussion). All conformers were found within a range of $5 \mathrm{kcal} \mathrm{mol}^{-1}$. The structures of the most stable conformer of the resulting active catalyst (16e) are collected in Figure 3 for the two catalysts. 

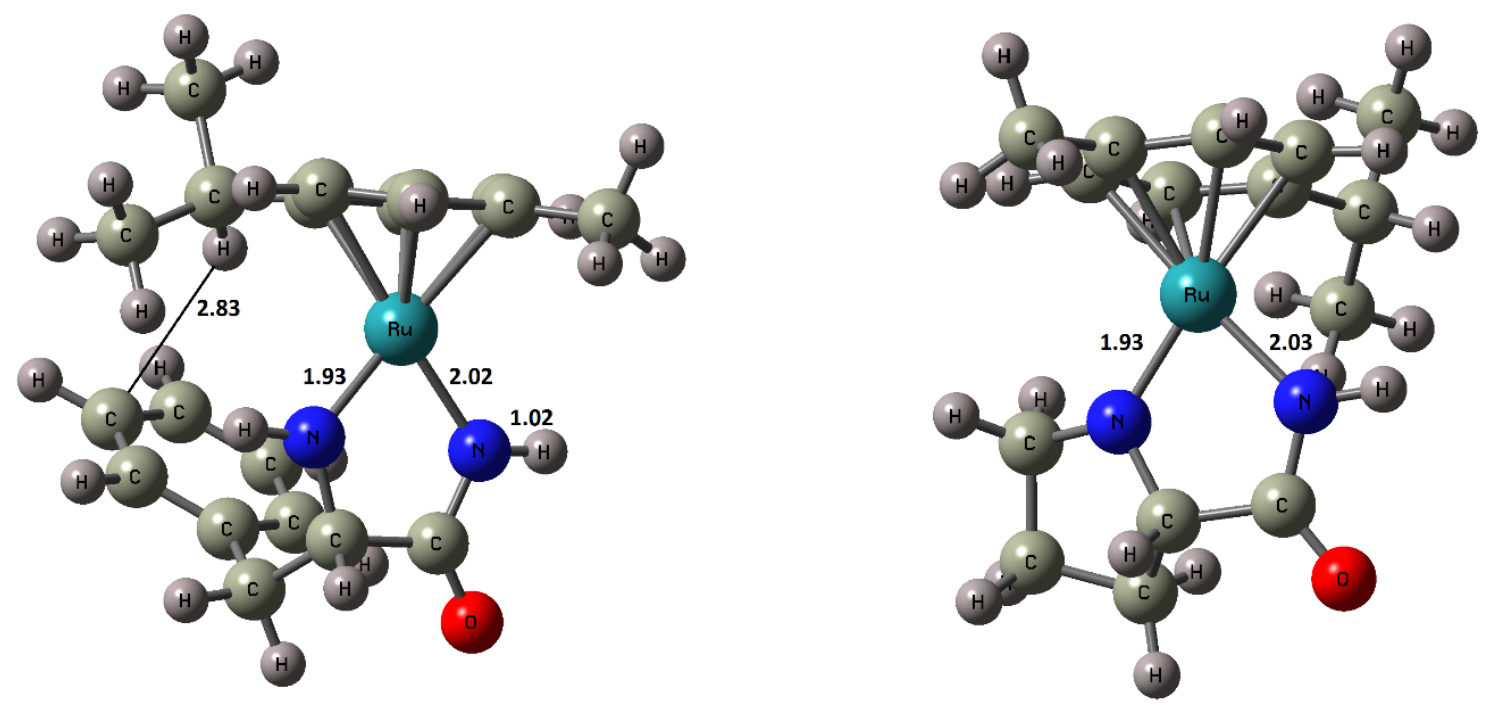

Figure 3. 16e Ruthenium active catalyst optimized geometries at the M06 level. Left: Cat-1 (ligand 1); right: Cat-2 (ligand 2). Distances in $\AA$. Atom color code: $\mathrm{H}$ in grey, $\mathrm{C}$ in green, $\mathrm{N}$ in blue and $\mathrm{O}$ in red.

\section{2- Formation of the 18e Ruthenium bi-functional complex:}

We considered the concerted mechanism in the following. In each complex, the active catalyst is able to dehydrogenate propan-2-ol (IPA) from two different sides ( $S i$ and Re faces of Ru) to afford metal hydride diastereoisomers with $\mathrm{R} \mathrm{u}_{\mathrm{R}}$ and Rus configurations and acetone, leading to a total of two transition states and two hydrogenated catalysts for each ligand. The corresponding structures are collected in Figure 4 and Figure 5 together with the corresponding activation free energies.

\section{a) Precatalyst with the (N,N) Phenylalanine (ligand 1)}

TSa-1-(S) results from the approach of IPA to the $R e$ face of the active catalyst (16e-phenylalanine) and leads to the $S$ configuration of the Ruthenium center in the hydrogenated catalyst $\left[\left(\eta^{6}-p-c y m e n e\right)-R u\left(\kappa^{2}-N, N^{\prime}-\right.\right.$ phenylalanine-amidato)H] Int-1-(S) (Figure 4). The free energy of TSa-1-(S) is $19.6 \mathrm{kcal} / \mathrm{mol}$ above that of the separate reactants (Cat-1 and IPA). TSa-1- $(R)$ results from the approach of IPA to the Si face of the Ruthenium atom and lies $20.5 \mathrm{kcal} / \mathrm{mol}$ above the free energy of the reactants. It leads to the $R$ configuration of the hydrogenated catalyst Int-1-(R) (Figure 4).

The reaction is slightly exergonic: the free energy of the hydrogenated catalysts (18e) with $R$ and $S$ configurations lies -0.8 and $-1.3 \mathrm{kcal} / \mathrm{mol}$, respectively, below the reactants (Cat-1 and IPA). The reason for this preference for both TSa-1(S) and the related hydrogenated catalyst Int-1-(S) is due to a stabilizing $\mathrm{CH}-\pi$ interaction between the phenyl group and the cymene ring of the catalyst (Figure 4). 


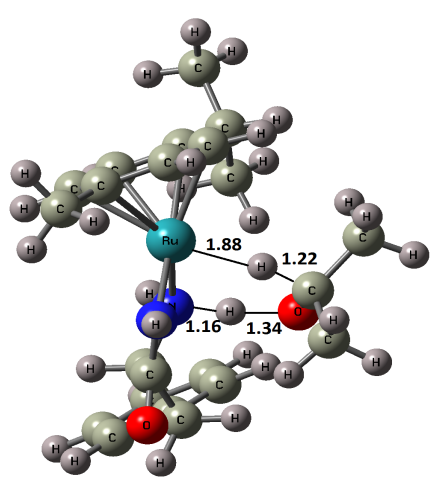

TSa-1-(R)

$\Delta G^{\ddagger}=20.5 \mathrm{kcal} / \mathrm{mol}$

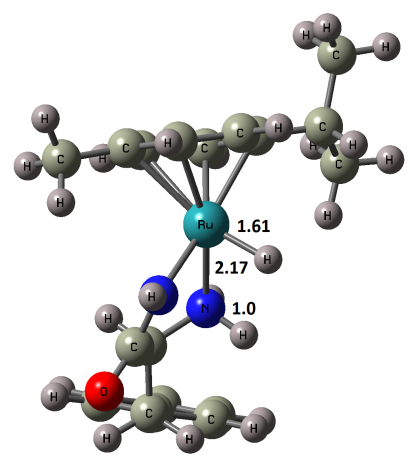

Int-1-(R)

$\Delta G^{0}=-0.8 \mathrm{kcal} / \mathrm{mol}$

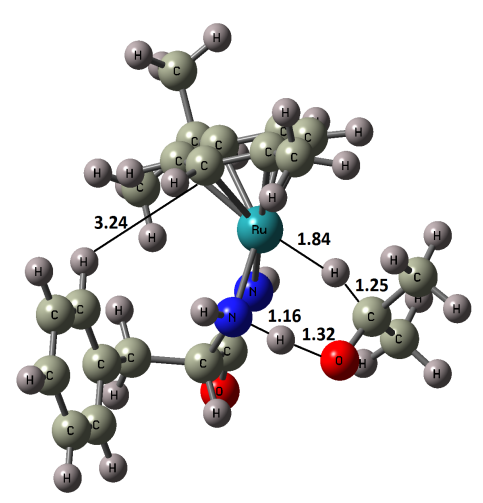

TSa-1-(S)

$\Delta G^{\ddagger}=19.6 \mathrm{kcal} / \mathrm{mol}$

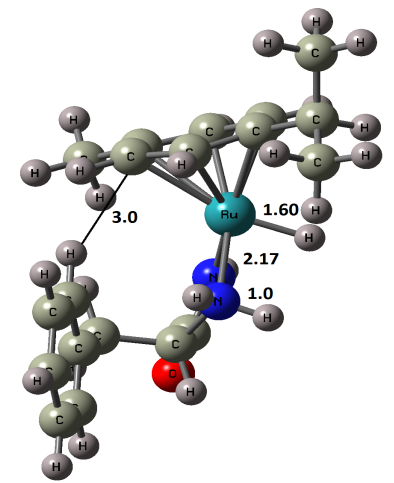

Int-1-(S)

$\Delta G^{0}=-1.2 \mathrm{kcal} / \mathrm{mol}$

Figure 4: Optimized geometries of transition states and of the hydrogenated catalyst (18e Ruphenylalanine) for the concerted H-transfer from isopropanol to the (16e-phenylalanine).

\section{b) Precatalyst with the $(\mathrm{N}, \mathrm{N})$ proline amide (ligand 2)}

TSa-2- $(S)$ and TSa-2- $(R)$ result from the approach of IPA to the Re and Si face of the Ru of Cat-2 and leads to the corresponding hydrogenated catalysts Int-2-(S) and Int-2-(R), respectively (Figure 5). The free energy of TSa-2-(S) and TSa-2- $(R)$ is calculated to lie respectively 21.9 and $23.5 \mathrm{kcal}^{-\mathrm{mol}^{-1}}$ above that of the separate reactants (Cat-2 and IPA).

The free energy of the two hydrogenated catalysts lies $-1.3 \mathrm{kcal}_{\mathrm{mol}}{ }^{-1}$ below the free energy of separate reactants (Cat-2 and IPA) for $S$ configuration and $3.0 \mathrm{kcal}^{\mathrm{mol}}{ }^{-1}$ for $R$ configuration above the free energy of separate reactants. Both TSa-2-(R) and Int-2-(R) suffer from destabilizing interactions between the Ru-N-C$\mathrm{C}(\mathrm{O})-\mathrm{N}$ chelation ring and the isopropyl group of cymene ring that cannot be released by rotation of the $p$ cymene. 


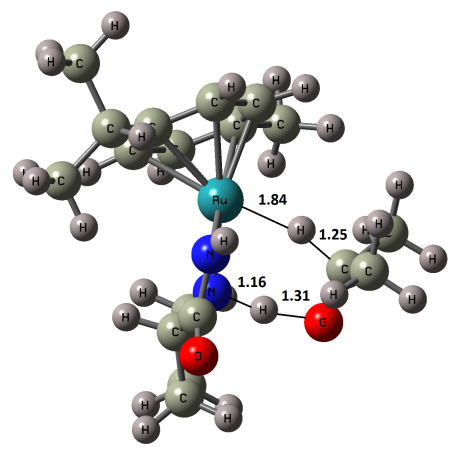

TSa-2-(R)

$\Delta G^{\ddagger}=23.5 \mathrm{kcal} / \mathrm{mol}$

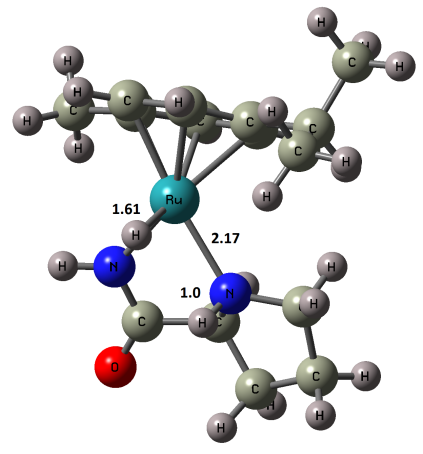

Int-2-(R)

$\Delta G^{0}=3.0 \mathrm{kcal} / \mathrm{mol}$

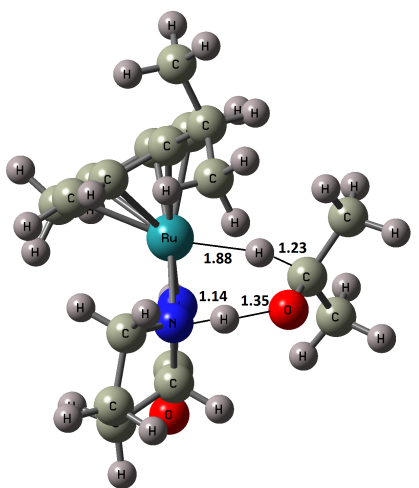

TSa-2-(S)

$\Delta G^{\ddagger}=21.9 \mathrm{kcal} / \mathrm{mol}$

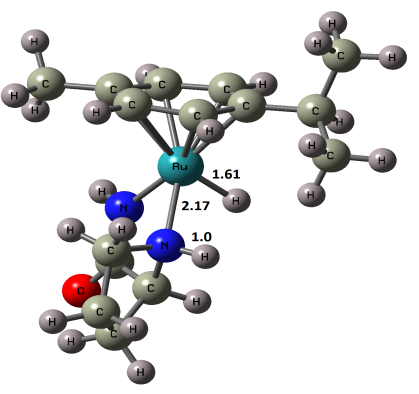

Int-2-(S)

$\Delta G^{0}=-1.3 \mathrm{kcal} / \mathrm{mol}$

Figure 5. Optimized geometries of transition states and of the hydrogenated catalyst for the concerted H-transfer from isopropanol to 16e-proline.

\section{3- Asymmetric transfer hydrogenation of acetophenone}

The $\mathrm{H}$-transfer from the 18e-Ruthenium bi-functional complexes to the acetophenone can occur either at the Re face or at the Si face of the acetophenone. This results in a total of four transition states TSbRR, TSbRS, TSbSR, and TSbSS depending on the Ruthenium absolute configuration and the resulting configuration of the asymmetric carbon in phenylethanol. We systematically investigated various conformers for each case, which gave a total of 68 TSs starting from Int-1 and 12 TSs from Int-2. The relative free energies of these transition states for all investigated conformers of the active catalysts are collected in Table S3 and Table S4 respectively (supporting information). We discuss in the following the reaction profile obtained with the lowest conformer for each transition state since the energetic difference between the conformers is low enough to allow reaching the thermodynamic equilibrium.

\section{a) (N,N)Phenylalanine (ligand 1$)$}

Figure 6 displays the overall Gibbs free energy profiles of the asymmetric transfer hydrogenation of acetophenone using phenylalanine amide as the ligand. Corresponding structures can be found in Figure 4 and 7. 
As seen in the previous part, Int-1-(S) is more stable than Int-1-(R). The simultaneous transfer of the amine proton and the hydride to acetophenone leads to the formation of $R$-phenylethanol or $S$-phenylethanol via TSb-1-(SR) and TSb-1-(SS) that lie at 17.8 and $19.0 \mathrm{kcal} / \mathrm{mol}$, respectively, above the reactants. Similarly, the hydrogenated catalyst Int-1-(R) interacts with the $\mathrm{C}=\mathrm{O}$ double bond of acetophenone which leads to the formation of $R$-phenylethanol or S-phenylethanol via TSb-1-(RS) and TSb-1-(RR) which lie 19.4 and 19.8 $\mathrm{kcal} / \mathrm{mol}$, above reactants. The greater stability of the Int-1-(S) is maintained in the hydrogen transfer transition states and is accompanied by a conformational adjustment of the $p$-cymene and the phenyl substituent of the phenylalanine.

In addition, looking at activation energies for the second step, we can see that the one corresponding to the hydrogenated catalyst Int-1-(R) gives preferentially the $S$ isomer of phenylethanol via TSb-1-(RS) with a barrier of $20.2 \mathrm{kcal} / \mathrm{mol}$. In the other hand, the hydrogenated catalyst Int-1-(S) gives preferentially the $R$ isomer of phenylethanol via TSb-1-(SR) with a barrier of $19.0 \mathrm{kcal} / \mathrm{mol}$.

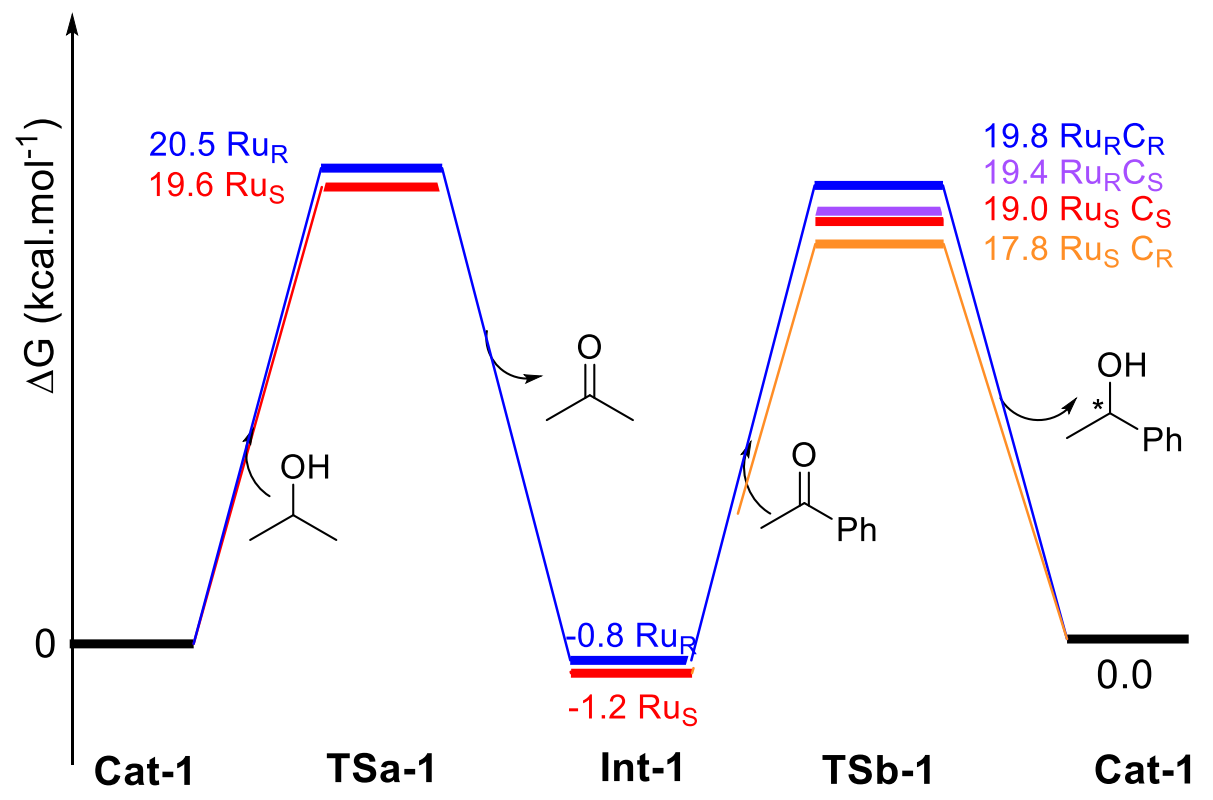

Figure 6. Gibbs free energy profiles $(\mathrm{kcal} / \mathrm{mol})$ for the asymmetric hydrogenation reaction of acetophenone using phenylalanine-amide as ligand. The reference free energy is the sum of the free energies of the active catalyst Cat-1 and the separate reactants (propan-2-ol and acetophenone). 

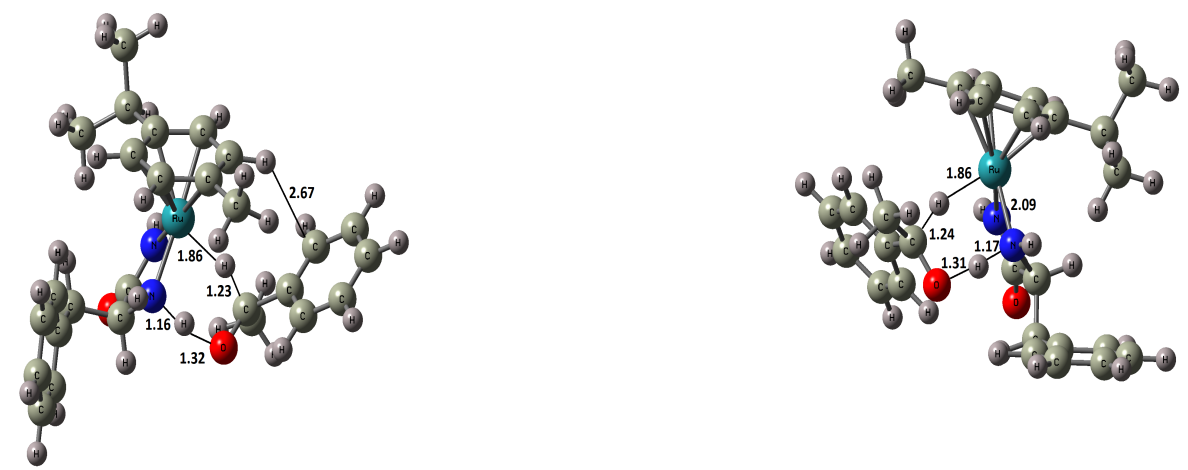

TSb-1-(SR)

$\Delta G^{\ddagger}=17.8 \mathrm{kcal} / \mathrm{mol}$

TSb-1-(RR)

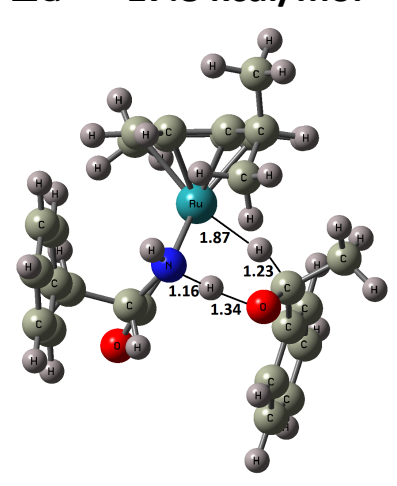

$\Delta G^{\ddagger}=19.8 \mathrm{kcal} / \mathrm{mol}$

TSb-1-(SS)

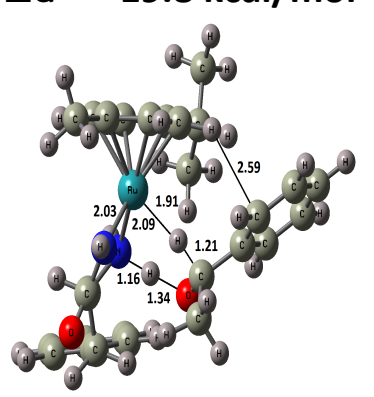

$\Delta G^{\ddagger}=19.0 \mathrm{kcal} / \mathrm{mol}$

TSb-1-(RS)

$\Delta G^{\ddagger}=19.4 \mathrm{kcal} / \mathrm{mol}$

Figure 7. Optimized geometries of the transition states of the hydrogen transfer from Int-1 to acetophenone. Distances are given in $\AA$.

As already examined by Noyori, the lower barrier for the transition state TSb-1-(SR) is partly due to a stabilizing $\mathrm{CH}-\pi$ interaction between the phenyl group of acetophenone and the $p$-cymene ligand (distance

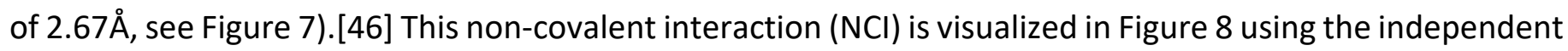
gradient model.[47,48] For comparison with the other transition states, the same visualization is provided in supplementary materials.

(a)

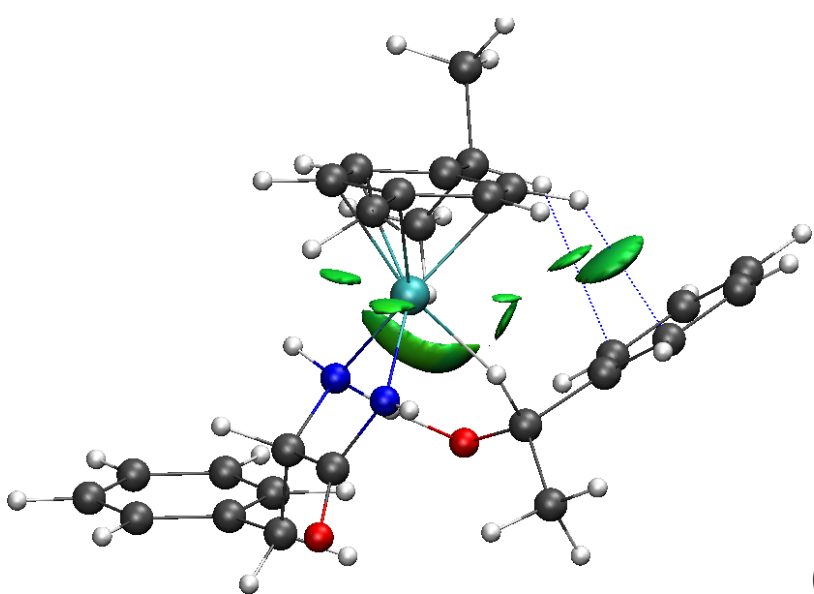

(b)

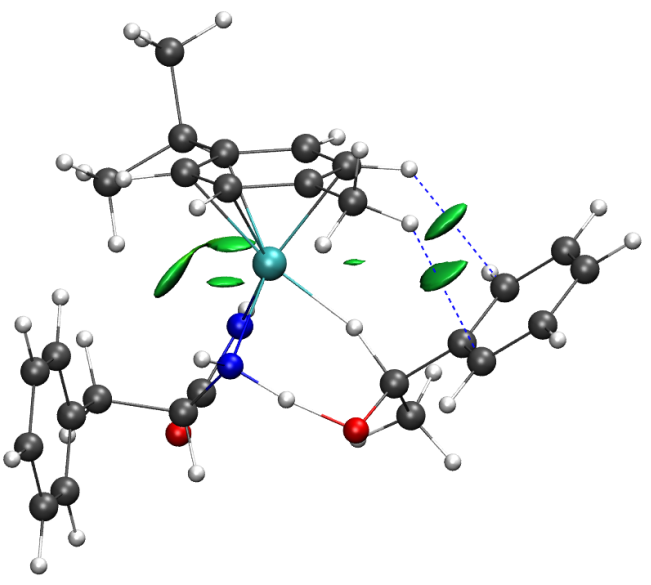

Figure 8. Visualization of the non covalent $\mathrm{CH}-\pi$ interactions (as green maps) between the $p$-cymene 
ligand and the ketone (a) TSb-1-(RS) (b) TSb-1-(SR). Color code: Ru in cyan, Carbon in gray, Oxygen in red, Nitrogen in blue, Hydrogen in white.

The generation of the $S$ isomer of phenylethanol from the Int-1-(S) hydrogenated catalyst requires overcoming a barrier of $20.5 \mathrm{kcal}^{\mathrm{mol}}{ }^{-1}$. Thus, it appears that the lowest barrier leading to the $R$ phenyl ethanol is $19.0 \mathrm{kcal} / \mathrm{mol}$ (TSb-1-(SR)), whereas the lowest barrier leading to the $S$ phenyl ethanol is 20.2 $\mathrm{kcal} / \mathrm{mol}^{-1}$ (TSb-1-(RS)). Our calculations correctly reproduce the fact that the ligand phenylalanine favors the $R$ isomer. However, under kinetic control, and considering only the energy difference between the lowest barriers $(1.2 \mathrm{kcal} / \mathrm{mol})$, this catalyst should lead to an ee of $78 \%$ in favor of the $\mathrm{R}$ isomer. This first theoretical estimate is much higher than the experimental value (ee=30\%). This surely comes from the fact that the barriers are low enough for the system to evolve towards the thermodynamic equilibrium in which the enantiomeric excess would be zero. This is consistent with the very high experimental conversion ( $C=97 \%$ ) and with the results of Bacchi et al.: they found a lower ee for higher temperature.[22] To confirm this, we performed a kinetic simulation of the catalytic cycle including all reactions:

$$
\begin{aligned}
& k_{a s}
\end{aligned}
$$

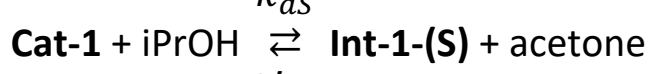

$$
\begin{aligned}
& k^{\prime}{ }_{a s} \\
& k_{a R} \\
& \text { Cat-1 + iPrOH } \rightleftarrows \text { Int-1-(R) + acetone } \\
& k_{a R}^{\prime} \\
& k_{b R R} \\
& \text { Int-1-(R) + PhC(=O)Me } \underset{k_{b R R}^{\prime}}{\rightleftarrows} \text { Cat-1 + R-PhCH(OH)Me } \\
& k_{b R S} \\
& \text { Int-1-(R) + PhC(=O)Me } \rightleftarrows \text { Cat-1 + S-PhCH(OH)Me } \\
& k^{\prime}{ }_{b R S} \\
& k_{b S R} \\
& \text { Int-1-(S) + PhC(=O)Me } \rightleftarrows \text { Cat-1 + R-PhCH(OH)Me } \\
& k^{\prime}{ }_{b S R} \\
& k_{b R S} \\
& \text { Int-1-(S) + PhC(=O)Me } \rightleftarrows \text { Cat-1 + S-PhCH(OH)Me } \\
& k^{\prime}{ }_{b R S}
\end{aligned}
$$

The rate constants were computed using the Eyring formula at $30^{\circ} \mathrm{C}$. The initial conditions were set to the experimental ones: [Cat-1] $=510^{-4} \mathrm{~mol} / \mathrm{L},[\mathrm{PhC}(=0) \mathrm{Me}]=0.1 \mathrm{~mol} / \mathrm{L}$ in isopropanol. The simulation was performed using Copasi[49,50] and the time evolution of the conversion and enantiomeric excess is given in Figure 9. This confirms that as soon as the conversion is close to $100 \%$, the system evolves towards thermodynamic equilibrium and the enantiomeric excess decreases, in agreement with the experimental value. 


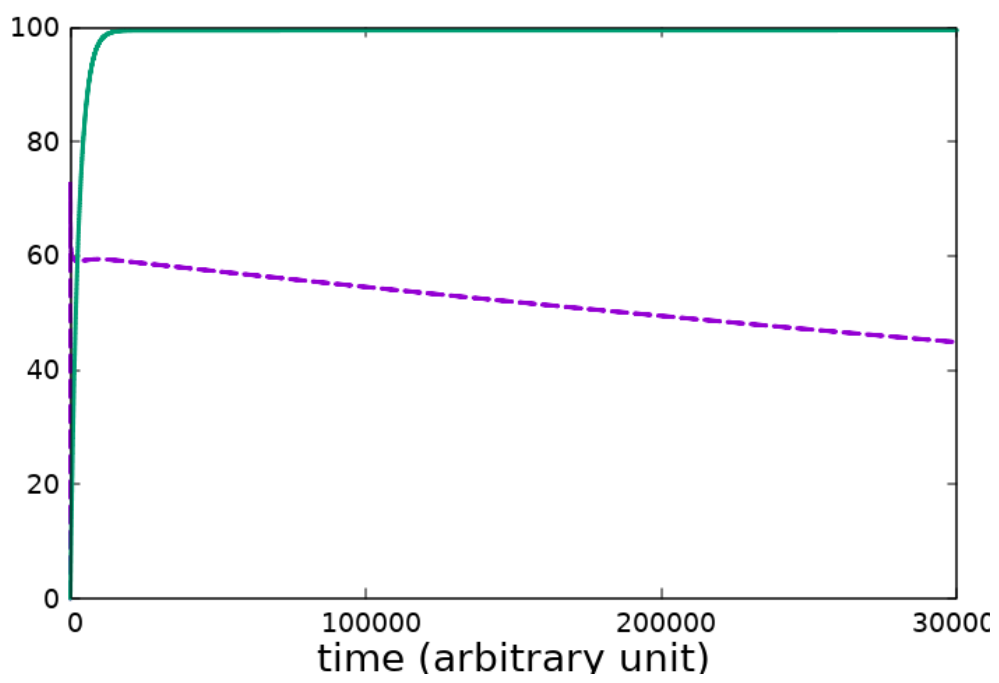

Figure 9. Time evolution (in arbitrary units) of the conversion (in green) and of the enantiomeric excess (dashed purple line) for the hydrogenation of acetophenone using phenylalanine amide ligand.

\section{b) (N,N)proline amide (ligand 2)}

Figure 10 displays the overall Gibbs free energy profiles of the asymmetric transfer hydrogenation of acetophenone using proline amide as ligand. Corresponding structures can be found in Figures 5 and 11 . When the hydrogenated catalyst Int-2-(S) interacts with the $\mathrm{C}=\mathrm{O}$ double bond of acetophenone, the simultaneous transfer of the amine proton and hydride to the acetophenone leads to the formation of $R$ phenylethanol or S-phenylethanol and takes place via TSb-2-(SR) and TSb-2-(SS), which lie at 19.2 and 20.3 $\mathrm{kcal} / \mathrm{mol}$, respectively, above reactants. Similarly, the hydrogenated catalyst Int-2-(R) interacts with the $\mathrm{C}=\mathrm{O}$ double bond of acetophenone which leads to the formation of $R$-phenylethanol or S-phenylethanol via TSb-

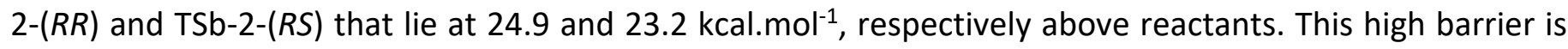
due to the interactions between the Ru-N-C-C(O)-N chelation ring and the isopropyl group of cymene ring. If we look at the energy levels of TSb-2-(SS) and TSb-2-(SR), we can see that TSb-2-(SR) lies $1.1 \mathrm{kcal} / \mathrm{mol}$ lower in energy than TSb-2-(SS), which suggests that the $\mathrm{H}$ transfer leads to the $R$ isomer of phenyl ethanol with a high selectivity. As seen previously, this is due to a stabilizing $\mathrm{CH}-\pi$ interaction between the phenyl group of acetophenone and the $p$-cymene ligand (shown in Supporting Informations). The energy difference between TSb-2-(SR) and TSb-2-(SS) (1.1 kcal/mol) leads to an enantiomeric excess of $73 \%$ in favor of the former, in very good agreement with the experimental selectivity (ee=74\%). 


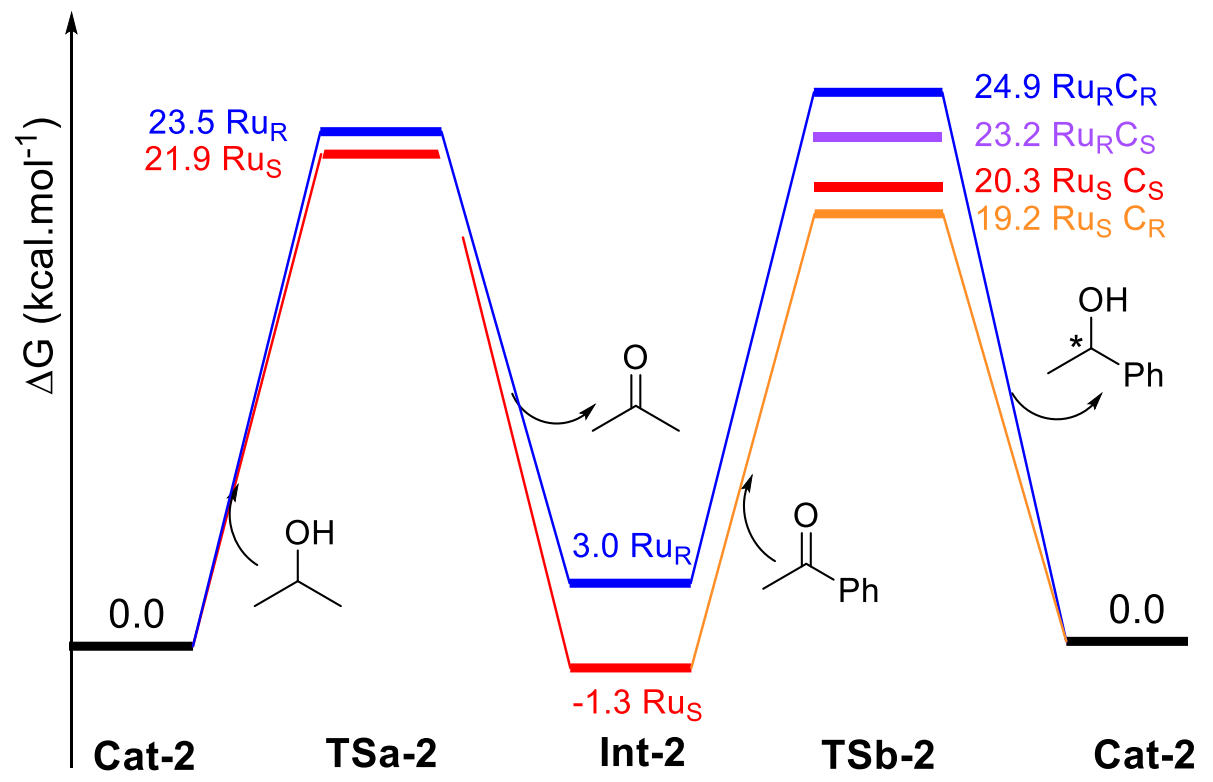

Figure 10. Gibbs free energy profiles $\left(\mathrm{kcal} \mathrm{mol}^{-1}\right)$ for the asymmetric hydrogenation reaction of acetophenone using proline-amide as ligand. The reference free energy is the sum of the free energies of the active catalyst Cat-2 and the separate reactants (propan-2-ol and acetophenone).

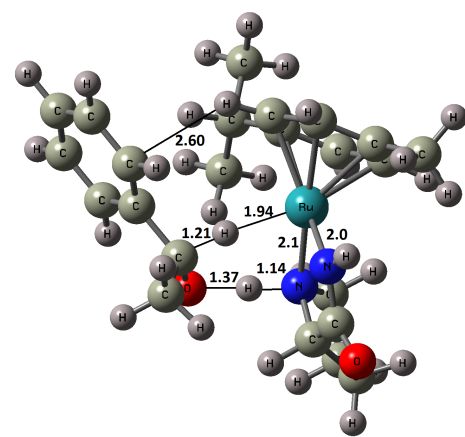

TSb-2-(SR)

$\Delta G^{\ddagger}=19.2 \mathrm{kcal} / \mathrm{mol}$

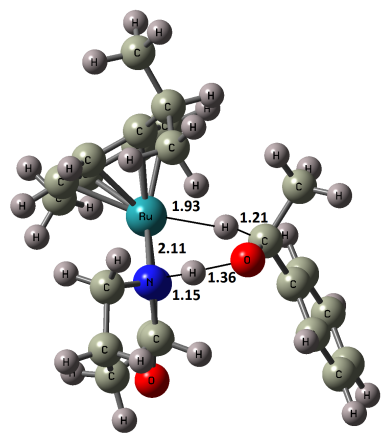

TSb-2-(SS)

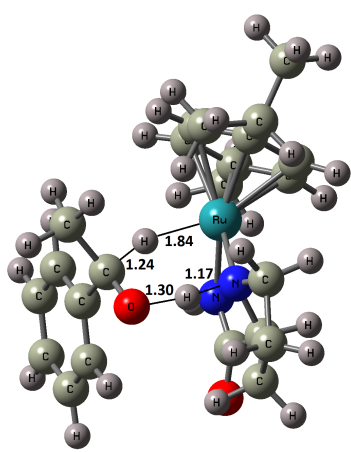

TSb-2-(RR) $\Delta G^{\ddagger}=24.9 \mathrm{kcal} / \mathrm{mol}$

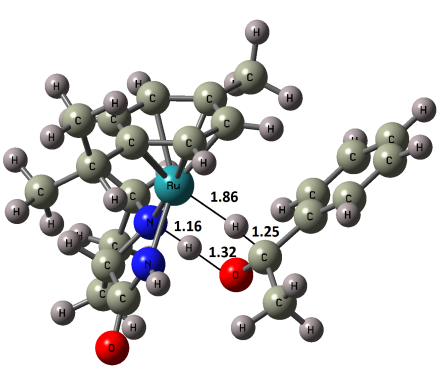

$\mathrm{TSb}-2-(R S)$

$\Delta G^{\ddagger}=23.2 \mathrm{kcal} / \mathrm{mol}$

Figure 11: Optimized geometries of the transition states of the hydrogen transfer from Int-2 to acetophenone. Distances are provided in $\AA$

Comparing the Gibbs free energy profiles for phenylalanine (Figure 6) and proline (Figure 10) ligands, we can conclude that the precatalyst ligated with phenylalanine amide should lead to a higher conversion because 
each activation barrier is much lower than the corresponding one with proline: $19.6 \mathrm{kcal} / \mathrm{mol}$ vs. 21.9 $\mathrm{kcal} / \mathrm{mol}$ for the first $\mathrm{H}$-transfer and $19.0 \mathrm{kcal} / \mathrm{mol} \mathrm{vs.} 20.2 \mathrm{kcal} / \mathrm{mol}$ for the second $\mathrm{H}$-transfer. This is in good agreement with the experimental results: the conversion equals $97 \%$ for phenylalanine ligand while, in the case of precatalyst liganded with proline amide the conversion is equal to $59 \%$ only. Simulation of the time evolution of the conversion and ee for the proline amide ligand (Figure 12) also confirms that these higher barriers result in a very slow decrease of the enantiomeric excess compared to the case of the phenylalanine ligand.

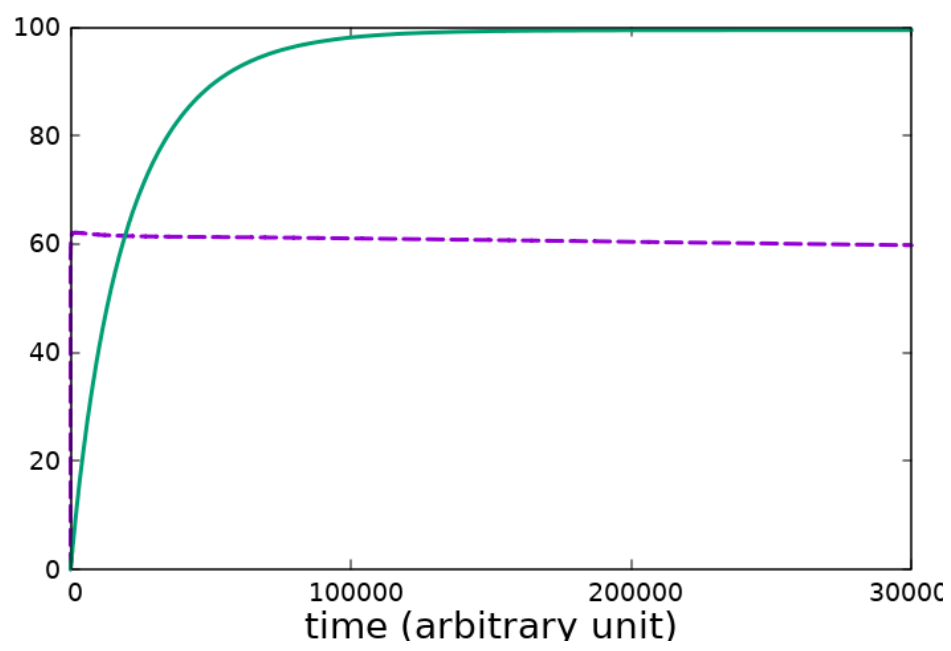

Figure 12. Time evolution (in arbitrary units) of the conversion (green plain) and of the enantiomeric excess (dashed purple) for the hydrogenation of acetophenone using phenylalanine amide ligand.

\section{CONCLUSION}

We have investigated in details the mechanism of the enantioselective reduction of the prochiral acetophenone promoted by amino amide ruthenium complexes using DFT calculations. The reaction mechanism proceeds in three steps, firstly, the formation of the active catalyst, then, the formation of the bifunctional ruthenium complex, and finally, the attack of the metal hydride at the Re face or the Si face of the acetophenone. Thanks to a careful analysis of the conformers accessible through the $p$-cymene rotation and the phenyl rotation in the phenylalanine group, we succeeded in reproducing the experimentally observed enantioselectivies and yields. For both phenylalanine and proline amide ligands, the R enantiomer was favored by a stabilizing $\mathrm{CH}-\pi$ interaction existing between the phenyl group of acetophenone and the cymene ring of the catalyst. Study of these Non Covalent Interactions $(\mathrm{NCl})$ confirmed the importance of these weak interactions. Our calculations also revealed that the activation barriers for all steps of the catalytic cycle are higher for the proline amide ligand compared to the phenylalanine amide. These higher barriers are at the origin of the higher enantioselectivity $(e e=76 \%)$ and lower yield $(C=59 \%)$ observed for the proline amide ligand, in agreement with the experiments. The catalytic cycle for phenylalanine amide ligand proceeded through lower barriers (less than $20.5 \mathrm{kcal} / \mathrm{mol}$ ) in agreement with a very fast reaction ( $\mathrm{C}=97 \%$ ) and a lower enantiomeric excess. This study shows also that simple DFT calculations alone cannot explain 
the experimental ee values and that a kinetic study was necessary to explain the results.

\section{ACKNOWLEGMENTS}

We thank the SYSPROD project and AXELERA Pôle de Compétitivité for financial support (PSMN Data Center). Some calculations were also performed using HPC resources from DNUM CCUB (Centre de Calcul de l'Université de Bourgogne).

\section{REFERENCES}

[1] H.U. Blaser, C. Malan, B. Pugin, F. Spindler, H. Steiner, M. Studer, Selective Hydrogenation for Fine Chemicals: Recent Trends and New Developments, Adv. Synth. Catal. 345 (2003) 103-151. https://doi.org/10.1002/adsc.200390000.

[2] F. Naud, F. Spindler, C.J. Rueggeberg, A.T. Schmidt, H.U. Blaser, Enantioselective ketone hydrogenation: From R\&D to pilot scale with industrially viable Ru/phosphine-oxazoline complexes, Org. Process Res. Dev. 11 (2007) 519-523. https://doi.org/10.1021/op0601619.

[3] J.P.C. Coverdale, I. Romero-Canelón, C. Sanchez-Cano, G.J. Clarkson, A. Habtemariam, M. Wills, P.J. Sadler, Asymmetric transfer hydrogenation by synthetic catalysts in cancer cells, Nat. Chem. 10 (2018) 347-354. https://doi.org/10.1038/nchem.2918.

[4] R. Noyori, S. Hashiguchi, Asymmetric Transfer Hydrogenation Catalyzed by Chiral Ruthenium Complexes, Acc. Chem. Res. 30 (1997) 97-102. https://doi.org/10.1021/ar9502341.

[5] M.J. Palmer, M. Wills, Asymmetric transfer hydrogenation of $\mathrm{C}=\mathrm{O}$ and $\mathrm{C}=\mathrm{N}$ bonds, Tetrahedron Asymmetry. 10 (1999) 2045-2061. https://doi.org/10.1016/S0957-4166(99)00216-5.

[6] D. Wang, D. Astruc, The Golden Age of Transfer Hydrogenation, Chem. Rev. 115 (2015) 6621-6686. https://doi.org/10.1021/acs.chemrev.5b00203.

[7] A.J. Argüelles, S. Sun, B.G. Budaitis, P. Nagorny, Design, Synthesis, and Application of Chiral C2Symmetric Spiroketal-Containing Ligands in Transition-Metal Catalysis, Angew. Chemie - Int. Ed. 57 (2018) 5325-5329. https://doi.org/10.1002/anie.201713304.

[8] Y. Bin Wang, P. Yu, Z.P. Zhou, J. Zhang, J. (Joelle) Wang, S.H. Luo, Q.S. Gu, K.N. Houk, B. Tan, Rational design, enantioselective synthesis and catalytic applications of axially chiral EBINOLs, Nat. Catal. 2 (2019) 504-513. https://doi.org/10.1038/s41929-019-0278-7. 
[9] S. Hashiguchi, A. Fujii, J. Takehara, T. Ikariya, R. Noyori, Asymmetric Transfer Hydrogenation of Aromatic Ketones Catalyzed by Chiral Ruthenium(II) Complexes, J. Am. Chem. Soc. 117 (1995) 75627563. https://doi.org/10.1021/ja00133a037.

[10] T. Ohta, S.I. Nakahara, Y. Shigemura, K. Hattori, I. Furukawa, $\alpha$-amino acid: An effective ligand for asymmetric catalysis of transfer hydrogenation of ketones, Appl. Organomet. Chem. 15 (2001) 699709. https://doi.org/10.1002/aoc.216.

[11] J.W. Faller, A.R. Lavoie, Catalysts for the Asymmetric Transfer Hydrogenation of Ketones Derived from I-Prolinamide and $(p \text {-cymeneRuCl })_{2}$ or $\left(\mathrm{Cp}^{*} \mathrm{RhCl}_{2}\right)_{2}$, Organometallics. 20 (2001) 5245-5247. https://doi.org/10.1021/om010644v.

[12] H.Y. Rhyoo, H.J. Park, Y.K. Chung, The first Ru(II)-catalysed asymmetric hydrogen transfer reduction of aromatic ketones in aqueous media, Chem. Commun. 1 (2001) 2064-2065. https://doi.org/10.1039/b106130p.

[13] H.Y. Rhyoo, Y.A. Yoon, H.J. Park, Y.K. Chung, Use of amino amides derived from proline as chiral ligands in the ruthenium(II)-catalyzed transfer hydrogenation reaction of ketones, Tetrahedron Lett. 42 (2001) 5045-5048. https://doi.org/10.1016/S0040-4039(01)00914-5.

[14] J. Mao, J. Guo, Chiral amino amides for the ruthenium(II)-catalyzed asymmetric transfer hydrogenation reaction of ketones in water, Chirality. 22 (2010) 173-181. https://doi.org/10.1002/chir.20723.

[15] Z. Zhou, L. Wu, Proline-based amino amide hydrochlorides as ligands for asymmetric transfer hydrogenation of prochiral ketones in water, Catal. Commun. 9 (2008) 2539-2542. https://doi.org/10.1016/j.catcom.2008.07.001.

[16] S. Zeror, J. Collin, J.-C. Fiaud, L.A. Zouioueche, Evaluation of Ligands for Ketone Reduction by Asymmetric Hydride Transfer in Water by Multi-Substrate Screening, Adv. Synth. Catal. 350 (2008) 197-204. https://doi.org/10.1002/adsc.200700272.

[17] M. Boukachabia, S. Zeror, J. Collin, J.-C. Fiaud, L.A. Zouioueche, Screening method for the evaluation of asymmetric catalysts for the reduction of aliphatic ketones, Tetrahedron Lett. 52 (2011) 14851489. https://doi.org/10.1016/j.tetlet.2011.01.112.

[18] A.B. Zaitsev, H. Adolfsson, Enantioswitchable catalysts for the asymmetric transfer hydrogenation of aryl alkyl ketones., Org. Lett. 8 (2006) 5129-32. https://doi.org/10.1021/ol062227q.

[19] V.K. Vyas, P. Srivastava, P. Bhatt, V. Shende, P. Ghosh, B.M. Bhanage, Highly Enantioselective One- 
Pot Synthesis of Chiral $\beta$-Heterosubstituted Alcohols via Ruthenium-Prolinamide-Catalyzed Asymmetric Transfer Hydrogenation, ACS Omega. 3 (2018) 12737-12745.

https://doi.org/10.1021/acsomega.8b01316.

[20] K. Ahlford, H. Adolfsson, Amino acid derived amides and hydroxamic acids as ligands for asymmetric transfer hydrogenation in aqueous media, Catal. Commun. 12 (2011) 1118-1121. https://doi.org/10.1016/j.catcom.2011.03.032.

[21] S. Denizaltı, D. Mercan, B. Şen, A.G. Gökçe, B. Çetinkaya, Asymmetric transfer hydrogenation reaction in water: Comparison of chiral proline amide/amine ruthenium(II) complexes, 2014. https://doi.org/10.1016/j.jorganchem.2014.12.023.

[22] A. Bacchi, P. Pelagatti, C. Pelizzi, D. Rogolino, Diastereomeric half-sandwich Ru(II) cationic complexes containing amino amide ligands. Synthesis, solution properties, crystal structure and catalytic activity in transfer hydrogenation of acetophenone, J. Organomet. Chem. 694 (2009) 3200-3211. https://doi.org/10.1016/j.jorganchem.2009.05.010.

[23] V. Guiral, F. Delbecq, P. Sautet, Origin of the Enantioselectivity in the Hydrogen Transfer Reduction of Carbonyls by a Rhodium(I) Complex: A Theoretical Study, Organometallics. 20 (2001) 2207-2214. https://doi.org/10.1021/om010120v.

[24] F. Delbecq, V. Guiral, P. Sautet, Contribution of DFT Calculations to the Understanding of an Asymmetric Reaction, the Hydrogen Transfer Reduction of Ketones by a Rhodium(I) Complex, European J. Org. Chem. 2003 (2003) 2092-2097. https://doi.org/10.1002/ejoc.200200701.

[25] K.H. Hopmann, Quantum chemical studies of asymmetric reactions: Historical aspects and recent examples, Int. J. Quantum Chem. (2015) n/a-n/a. https://doi.org/10.1002/qua.24882.

[26] K.H. Hopmann, How to Make Your Computational Paper Interesting and Have It Published, Organometallics. 38 (2019) 603-605. https://doi.org/10.1021/acs.organomet.8b00942.

[27] S. Santoro, M. Kalek, G. Huang, F. Himo, Elucidation of Mechanisms and Selectivities of MetalCatalyzed Reactions using Quantum Chemical Methodology, (2016). https://doi.org/10.1021/acs.accounts.6b00050.

[28] J.N. Harvey, F. Himo, F. Maseras, L. Perrin, Scope and Challenge of Computational Methods for Studying Mechanism and Reactivity in Homogeneous Catalysis, ACS Catal. 9 (2019) 6803-6813. https://doi.org/10.1021/acscatal.9b01537.

[29] M. Foscato, V.R. Jensen, Automated in Silico Design of Homogeneous Catalysts, ACS Catal. 10 (2020) 
2354-2377. https://doi.org/10.1021/acscatal.9b04952.

[30] R. Feng, A. Xiao, X. Zhang, Y. Tang, M. Lei, Origins of enantioselectivity in asymmetric ketone hydrogenation catalyzed by a RuH2(binap)(cydn) complex: Insights from a computational study, J. Chem. Soc. Dalt. Trans. 42 (2013) 2130-2145. https://doi.org/10.1039/c2dt32210b.

[31] R. Abbel, K. Abdur-Rashid, M. Faatz, A. Hadzovic, A.J. Lough, R.H. Morris, A succession of isomers of ruthenium dihydride complexes. Which one is the ketone hydrogenation catalyst?, J. Am. Chem. Soc. 127 (2005) 1870-82. https://doi.org/10.1021/ja039396f.

[32] M. Nordin, R.Z. Liao, K. Ahlford, H. Adolfsson, F. Himo, Theoretical Study of Asymmetric Transfer Hydrogenation of Ketones Catalyzed by Amino Acid-Derived Rhodium Complexes, ChemCatChem. 4 (2012) 1095-1104. https://doi.org/10.1002/cctc.201200045.

[33] P. Pelagatti, M. Carcelli, F. Calbiani, C. Cassi, L. Elviri, C. Pelizzi, U. Rizzotti, D. Rogolino, Transfer hydrogenation of acetophenone catalyzed by half-sandwich ruthenium (II) complexes containing amino amide ligands. Detection of the catalytic intermediates by electrospray ionization mass spectrometry, Organometallics. 24 (2005) 5836-5844. https://doi.org/10.1021/om050519+.

[34] M. Yamakawa, H. Ito, R. Noyori, The metal-ligand bifunctional catalysis: A theoretical study on the ruthenium(II)-catalyzed hydrogen transfer between alcohols and carbonyl compounds, J. Am. Chem. Soc. 122 (2000) 1466-1478. https://doi.org/10.1021/ja991638h.

[35] R. Noyori, M. Yamakawa, S. Hashiguchi, Metal-ligand bifunctional catalysis: A nonclassical mechanism for asymmetric hydrogen transfer between alcohols and carbonyl compounds, J. Org. Chem. 66 (2001) 7931-7944. https://doi.org/10.1021/jo010721w.

[36] E. Pedrajas, J.A. Pino-Chamorro, M. Ferrer, M.J. Fernández-Trujillo, R. Llusar, M. Martínez, M.G. Basallote, A.G. Algarra, Benchmarking of DFT methods using experimental free energies and volumes of activation for the cycloaddition of alkynes to cuboidal Mo3S4 clusters, Int. J. Quantum Chem. 120 (2020) 1-12. https://doi.org/10.1002/qua.26353.

[37] Y. Zhao, D.G. Truhlar, The M06 suite of density functionals for main group thermochemistry, thermochemical kinetics, noncovalent interactions, excited states, and transition elements: Two new functionals and systematic testing of four M06-class functionals and 12 other function, Theor. Chem. Acc. 120 (2008) 215-241. https://doi.org/10.1007/s00214-007-0310-x.

[38] Y. Zhao, D.G. Truhlar, Density functionals with broad applicability in chemistry, Acc. Chem. Res. 41 (2008) 157-167. https://doi.org/10.1021/ar700111a. 
[39] P.J. Hay, W.R. Wadt, Ab initio effective core potentials for molecular calculations. Potentials for $\mathrm{K}$ to Au including the outermost core orbitale, J. Chem. Phys. 82 (1985) 299-310. https://doi.org/10.1063/1.448975.

[40] A. V. Marenich, C.J. Cramer, D.G. Truhlar, Universal solvation model based on solute electron density and on a continuum model of the solvent defined by the bulk dielectric constant and atomic surface tensions, J. Phys. Chem. B. 113 (2009) 6378-6396. https://doi.org/10.1021/jp810292n.

[41] S.F. Boys, F. Bernardi, The calculation of small molecular interactions by the differences of separate total energies. Some procedures with reduced errors, Mol. Phys. 19 (1970) 553-566. https://doi.org/10.1080/00268977000101561.

[42] M.J. Frisch, G.W. Trucks, H.B. Schlegel, G.E. Scuseria, M.A. Robb, J.R. Cheeseman, G. Scalmani, V. Barone, B. Mennucci, G.A. Petersson, H. Nakatsuji, M. Caricato, X. Li, H.P. Hratchian, A.F. Izmaylov, J. Bloino, G. Zheng, J.L. Sonnenberg, M. Hada, M. Ehara, K. Toyota, R. Fukuda, J. Hasegawa, M. Ishida, T. Nakajima, Y. Honda, O. Kitao, H. Nakai, T. Vreven, J.A. Montgomery, J.E. Peralta, F. Ogliaro, M. Bearpark, J.J. Heyd, E. Brothers, K.N. Kudin, V.N. Staroverov, R. Kobayashi, J. Normand, K. Raghavachari, A. Rendell, J.C. Burant, S.S. Iyengar, J. Tomasi, M. Cossi, N. Rega, J.M. Millam, M. Klene, J.E. Knox, J.B. Cross, V. Bakken, C. Adamo, J. Jaramillo, R. Gomperts, R.E. Stratmann, O. Yazyev, A.J. Austin, R. Cammi, C. Pomelli, J.W. Ochterski, R.L. Martin, K. Morokuma, V.G. Zakrzewski, G.A. Voth, P. Salvador, J.J. Dannenberg, S. Dapprich, A.D. Daniels, Farkas, J.B. Foresman, J. V Ortiz, J. Cioslowski, D.J. Fox, Gaussian 09, Revision D.01, Gaussian 09, Revis. D.01, Gaussian, Inc., Wallingford CT. (2009).

[43] R.Z. Liao, S. Santoro, M. Gotsev, T. Marcelli, F. Himo, Origins of Stereoselectivity in Peptide-Catalyzed Kinetic Resolution of Alcohols, ACS Catal. 6 (2016) 1165-1171. https://doi.org/10.1021/acscatal.5b02131.

[44] A.K. Vitek, T.M.E. Jugovic, P.M. Zimmerman, Revealing the Strong Relationships between Ligand Conformers and Activation Barriers: A Case Study of Bisphosphine Reductive Elimination, ACS Catal. (2020) 7136-7145. https://doi.org/10.1021/acscatal.0c00618.

[45] A. Matsuoka, C.A. Sandoval, M. Uchiyama, R. Noyori, H. Naka, Why p-cymene? Conformational effect in asymmetric hydrogenation of aromatic ketones with a n6-arene/ruthenium(II) catalyst, Chem. - An Asian J. 10 (2015) 112-115. https://doi.org/10.1002/asia.201402979.

[46] M. Yamakawa, I. Yamada, R. Noyori, $\mathrm{CH} / \pi$ attraction: The origin of enantioselectivity in transfer hydrogenation of aromatic carbonyl compounds catalyzed by chiral n6-arene-ruthenium(II) 
complexes, Angew. Chemie - Int. Ed. 40 (2001) 2818-2821. https://doi.org/10.1002/15213773(20010803)40:15<2818::AID-ANIE2818>3.0.CO;2-Y.

[47] C. Lefebvre, G. Rubez, H. Khartabil, J.C. Boisson, J. Contreras-García, E. Hénon, Accurately extracting the signature of intermolecular interactions present in the $\mathrm{NCl}$ plot of the reduced density gradient: Versus electron density, Phys. Chem. Chem. Phys. 19 (2017) 17928-17936. https://doi.org/10.1039/c7cp02110k.

[48] C. Lefebvre, H. Khartabil, J.C. Boisson, J. Contreras-García, J.P. Piquemal, E. Hénon, The Independent Gradient Model: A New Approach for Probing Strong and Weak Interactions in Molecules from Wave Function Calculations, ChemPhysChem. 19 (2018) 724-735.

https://doi.org/10.1002/cphc.201701325.

[49] COPASI 4.29, (2020) Build 228. http://copasi.org/. (accessed October 12, 2020).

[50] S. Hoops, R. Gauges, C. Lee, J. Pahle, N. Simus, M. Singhal, L. Xu, P. Mendes, U. Kummer, COPASI - A COmplex PAthway SImulator, Bioinformatics. 22 (2006) 3067-3074. https://doi.org/10.1093/bioinformatics/bt|485. 